\title{
A New Index for the Atlantic Meridional Overturning Circulation at $26^{\circ} \mathrm{N}$
}

\author{
A. DuCHEZ AND J. J.-M. HiRsChI \\ National Oceanography Centre Southampton, Southampton, United Kingdom \\ S. A. CUNNINGHAM \\ Scottish Marine Institute Oban, Argyll, Scotland \\ A. T. Blaker, H. L. BRyden, AND B. DE Cuevas \\ National Oceanography Centre Southampton, Southampton, United Kingdom \\ C. P. ATKINSON \\ National Oceanography Centre Southampton, Southampton, and Met Office Hadley Centre, Exeter, United Kingdom \\ G. D. MCCARThy, E. FrajkA-Williams, D. RAyner, AND D. SMEed \\ National Oceanography Centre Southampton, Southampton, United Kingdom \\ M. S. MIZIELINSKI \\ Met Office Hadley Centre, Exeter, United Kingdom
}

(Manuscript received 8 January 2013, in final form 11 December 2013)

\begin{abstract}
The Atlantic meridional overturning circulation (AMOC) has received considerable attention, motivated by its major role in the global climate system. Observations of AMOC strength at $26^{\circ} \mathrm{N}$ made by the Rapid Climate Change (RAPID) array provide the best current estimate of the state of the AMOC. The period 2004-11 when RAPID AMOC is available is too short to assess decadal variability of the AMOC. This modeling study introduces a new AMOC index (called $\mathrm{AMOC}_{\mathrm{SV}}$ ) at $26^{\circ} \mathrm{N}$ that combines the Florida Straits transport, the Ekman transport, and the southward geostrophic Sverdrup transport. The main hypothesis in this study is that the upper midocean geostrophic transport calculated using the RAPID array is also wind-driven and can be approximated by the geostrophic Sverdrup transport at interannual and longer time scales. This index is expected to reflect variations in the AMOC at interannual to decadal time scales. This estimate of the surface branch of the AMOC can be constructed as long as reliable measurements are available for the Gulf Stream and for wind stress. To test the reliability of the AMOC on interannual and longer time scales, two different numerical simulations are used: a forced and a coupled simulation. Using these simulations the $\mathrm{AMOC}_{\text {Sv }}$ captures a substantial fraction of the AMOC variability and is in good agreement with the AMOC transport at $26^{\circ} \mathrm{N}$ on both interannual and decadal time scales. These results indicate that it might be possible to extend the observation-based AMOC at $26^{\circ} \mathrm{N}$ back to the $1980 \mathrm{~s}$.
\end{abstract}

\section{Introduction}

The Atlantic meridional overturning circulation (AMOC) plays a major role in the heat budget of the North Atlantic.

Corresponding author address: Aurélie Duchez, National Oceanography Centre Southampton, European Way, Southampton SO14 3ZH, United Kingdom.

E-mail: a.duchez@noc.ac.uk
The heat carried by the AMOC accounts for one-quarter of the maximal global meridional heat transport required by the coupled ocean-atmosphere system to balance the global radiation budget (Wunsch 2005; Trenberth and Caron 2001).

Interest in the AMOC has been stimulated by the prospect of its gradual weakening during the twenty-first century as suggested by the climate model scenarios of the Fourth Assessment Report of the Intergovernmental Panel on Climate Change (IPCC). They consider it "very 
likely" that the AMOC will weaken by $25 \%$ or more owing to anthropogenic warming trends in the subarctic Atlantic (Houghton et al. 2001; Weaver et al. 2012), thus reducing the oceanic supply of heat to the North Atlantic region. Several model simulations also suggest natural AMOC variability on intraseasonal to multidecadal time scales (Biastoch et al. 2008; Delworth et al. 1993; Hirschi et al. 2007; Jayne and Marotzke 2001; Latif et al. 2004; Wunsch and Heimbach 2009).

The Rapid Climate Change (RAPID) mooring array is a purposefully designed transatlantic array for continuous measurements of the strength and structure of the AMOC at $26.5^{\circ} \mathrm{N}$ and its associated heat flux (Cunningham et al. 2007; Hirschi et al. 2003; Johns et al. 2011; Rayner et al. 2011). With 8 years of observations provided by this array (from April 2004 to April 2012), it is now possible to estimate the interannual variability of the AMOC (McCarthy et al. 2012), but there are not yet enough observations to resolve the decadal variability and detect any long-term changes.

Long-term AMOC observations are also needed for studies of AMOC predictability (Collins and Sinha 2003; Ortega et al. 2011; Persechino et al. 2013). Indeed, in the absence of real long-term observations of the AMOC, AMOC predictability experiments have hitherto been addressed exclusively in a perfect model framework (Matei et al. 2012).

In this paper, using ocean models only, we propose a new AMOC index (called $\mathrm{AMOC}_{\mathrm{SV}}$ ) at $26.5^{\circ} \mathrm{N}$ that combines Florida Straits transport (FST), Ekman transport (EKM), and geostrophic Sverdrup transport (GST). This estimate of the surface branch of the AMOC can be constructed back in time for the period when reliable measurements are available for the Florida Straits transport and for wind stress. The aim of this paper is to assess the $\mathrm{AMOC}_{\mathrm{SV}}$ at decadal to multidecadal time scales using numerical simulations from the Nucleus for European Modelling of the Ocean (NEMO) model.

The paper is organized as follows: section 2 describes the observations and model simulations that were used and defines the $\mathrm{AMOC}_{\mathrm{SV}}$, and section 3 is concerned with the results and assesses the $\mathrm{AMOC}_{\mathrm{SV}}$ in the model simulations. Finally, section 4 summarizes and discusses the main results of this paper.

\section{Data and methods}

a. Data

\section{1) ObServing The AMOC AT $26.5^{\circ} \mathrm{N}$}

Although real observations are not used in the paper, this paragraph describes the data used to compute the observed AMOC at $26^{\circ} \mathrm{N}$ as the $\mathrm{AMOC}_{\mathrm{SV}}$ is designed to be applied to the RAPID observations.

Since 2004, the strength and vertical structure of the AMOC have been measured at $26.5^{\circ} \mathrm{N}$ using a transatlantic array known as the RAPID/Meridional Overturning Circulation and Heatflux Array (MOCHA)/Western Boundary Time Series (WBTS) array (Rayner et al. 2011; hereafter called the RAPID array). The AMOC is computed as the sum of three components.

The first component is the northward Florida Straits transport. This transport has been monitored using a submarine cable and repeated ship sections nearly continuously since 1982. It is maintained as part of the National Oceanic and Atmospheric Administration WBTS project (Baringer and Larsen 2001; Meinen et al. 2010). The Florida Current cable and section data are made freely available on the Atlantic Oceanographic and Meteorological Laboratory web page (www.aoml.noaa.gov/phod/floridacurrent/).

The second component is the northward wind-driven Ekman transport, zonally integrated between the shelf off Abaco (Bahamas) and the African coast. This transport is estimated as the zonal integral of the zonal component of the wind stress from the Cross-Calibrated Multiplatform Product (CCMP) (Atlas et al. 2011) at $25.5^{\circ} \mathrm{N}$. This transport is applied in the top $100 \mathrm{~m}$.

Finally, the last component is the southward geostrophic upper midocean (UMO) transport computed using the moorings of the RAPID array (Cunningham et al. 2007; Kanzow et al. 2007). To monitor this transport, the principle of the array is to estimate the top-to-bottom zonally integrated geostrophic profile of northward velocity from measurements of temperature and salinity at the eastern (African continent) and western (Bahamas) boundaries of the array using the thermal wind relationship.

The combination of the velocity fields from the three components (Florida Straits, Ekman, and UMO geostrophic transport) forms the top-to-bottom meridional profile across $26.5^{\circ} \mathrm{N}$. In general, the corresponding net meridional mass transport across the full Atlantic section is not zero and in order to obtain an AMOC estimate, a spatially (but not temporally) constant correction (also called "compensation") is added to the velocity field to make the total (top to bottom) Florida Straits, Ekman, and geostrophic UMO transport equal zero, ensuring mass conservation (Kanzow et al. 2007).

Data are processed and made available through the RAPID website (www.rapid.ac.uk/rapidmoc) with a temporal resolution of $12 \mathrm{~h}$. From April 2004 to October 2012 the mean AMOC strength was $17.4 \pm$ $4.9 \mathrm{~Sv}\left(1 \mathrm{~Sv} \equiv 10^{6} \mathrm{~m}^{3} \mathrm{~s}^{-1}\right)$, the Florida Straits transport was $31.6 \pm 3.1 \mathrm{~Sv}$, Ekman transport was $3.2 \pm 3.4 \mathrm{~Sv}$, and the UMO transport was $-17.2 \pm 3.5 \mathrm{~Sv}$ (McCarthy et al. 2012). ${ }^{1}$ Extended details about the calculation

\footnotetext{
${ }^{1}$ Positive and negative numbers indicate northward and southward transports respectively.
} 
of the AMOC and its components are available in Rayner et al. (2011).

The RAPID observations are not used in this paper, but the transports of the AMOC and its components in the two NEMO simulations described in section 2 are computed using the same methods as for the RAPID observations.

\section{2) Simulation of the AMOC}

The two global ocean-sea ice model simulations used in this study were performed with the NEMO code (Madec 2008) in the global ORCA025 configuration setup in the DRAKKAR project (Barnier et al. 2006, 2007; http://www. drakkar-ocean.eu/). The horizontal resolution of the configuration grid is $1 / 4^{\circ}(1442 \times 1021$ grid points). At the equator the resolution is approximately $27.75 \mathrm{~km}$ (around $25 \mathrm{~km}$ at $26^{\circ} \mathrm{N}$ ), becoming finer at higher latitudes such that at $60^{\circ} \mathrm{N} / \mathrm{S}$ it becomes $13.8 \mathrm{~km}$. The ORCA025 configuration used to run both simulations has 75 vertical levels with a grid spacing increasing from $1 \mathrm{~m}$ near the surface to $200 \mathrm{~m}$ at $5500 \mathrm{~m}$. Bottom topography is represented as partial steps and the bathymetry is derived from 2' Gridded Global Relief Data (ETOPO2) (National Geophysical Data Center 2006).

The first simulation starts from rest and covers the period 1958-2007. The surface forcing comprises 6-hourly mean momentum fields, daily mean radiation fields, and monthly mean precipitation fields supplied by the Coordinated Ocean-Ice Reference Experiments phase 2 (CORE2) dataset (Large and Yeager 2009) and linearly interpolated onto 6-hourly forcing values. The horizontal resolution of the atmosphere is $2.5^{\circ}$. Model output is stored as 5-day means. To prevent excessive drifts in global salinity due to deficiencies in the freshwater forcing, sea surface salinity is relaxed toward the World Ocean Atlas climatology with a piston velocity of $33.33 \mathrm{~mm} \mathrm{day}^{-1} \mathrm{psu}^{-1}$. Sea ice is represented by the Louvain-la-Neuve Sea Ice Model version 2 (LIM2) (Timmermann et al. 2005). Hereafter, this simulation will be referred to as "forced."

The second simulation is a coupled 100-yr simulation performed with the high-resolution version of the HadGEM3 model [as described by Hewitt et al. (2011)]. The atmosphere component is the Global Atmosphere version 3.0 (GA3.0) (Walters et al. 2011) and NEMO version 3.2 is used as the ocean component. Sea ice is represented by the Los Alamos sea ice model (CICE) version 4.1 and the Ocean Atmosphere Sea Ice Soil model version 3 (OASIS3) is used for the coupling

\footnotetext{
${ }^{2}$ For clear reference, this simulation is referred to as ORCA025N206 in the DRAKKAR dataset.
}

between atmosphere and ocean-sea ice (Hunke et al. 2013; Valcke 2006). Hereafter, this simulation will be referred to as "coupled.",

The ocean circulation in these simulations thus mainly differs by having an imposed (in the forced run) versus coupled approach (in the coupled run) to the atmospheric forcing. In the framework of this study focusing on wind-driven transports, the interest in using these two simulations is to show that the $\mathrm{AMOC}_{\mathrm{SV}}$ [which will be described in section $2 b(3)$ ] is valid regardless of the nature of the atmospheric forcing applied.

Figure 1 compares the AMOC time series in both simulations. The thick red and blue lines represent 1-yr smoothed data, and the thin gray line on the top panel represents 5-day means. The standard deviations of these transports are shown in Table 3 and demonstrate that the variability of the AMOC using 5-day means is 3 times higher than using 1-yr smoothed data. The red lines represent the AMOC computed as in RAPID observations, and the blue lines represent the AMOC computed as a full zonal integral of the meridional velocities. Both methods show similar results and the same method as for RAPID observations is used for the computation of the AMOC in this paper. In both simulations, the AMOC does not display any significant trend. However, there is interannual variability with cycles that typically last between 5 and 10 years.

\section{b. Methodology}

\section{1) A NEW APPROXIMATION OF THE UPPER MIDOCEAN TRANSPORT}

Using the AMOC decomposition described in section $2 \mathrm{a}(1)$, it is only possible to assess the AMOC transport since April 2004. The Florida Straits transport and Ekman transport are available since 1982 but the UMO transport cannot be estimated prior to the start of the RAPID program.

In the midocean at $26^{\circ} \mathrm{N}$, the upper ocean flow consists of generally northward Ekman transport and southward geostrophic transport in the thermocline. The surface Ekman transport is wind driven and is proportional to the zonal wind stress associated with the trade winds.

Our main hypothesis in this study is that the southward geostrophic thermocline flow (called UMO transport) is also driven by the wind. Indeed, it is considered to be proportional to the curl of wind stress associated with the anticyclonic winds over the subtropical gyre. In a stratified ocean, the curl of the wind stress, through Ekman

\footnotetext{
${ }^{3}$ This simulation is referred to as ORCA025-N216 in the DRAKKAR dataset.
} 


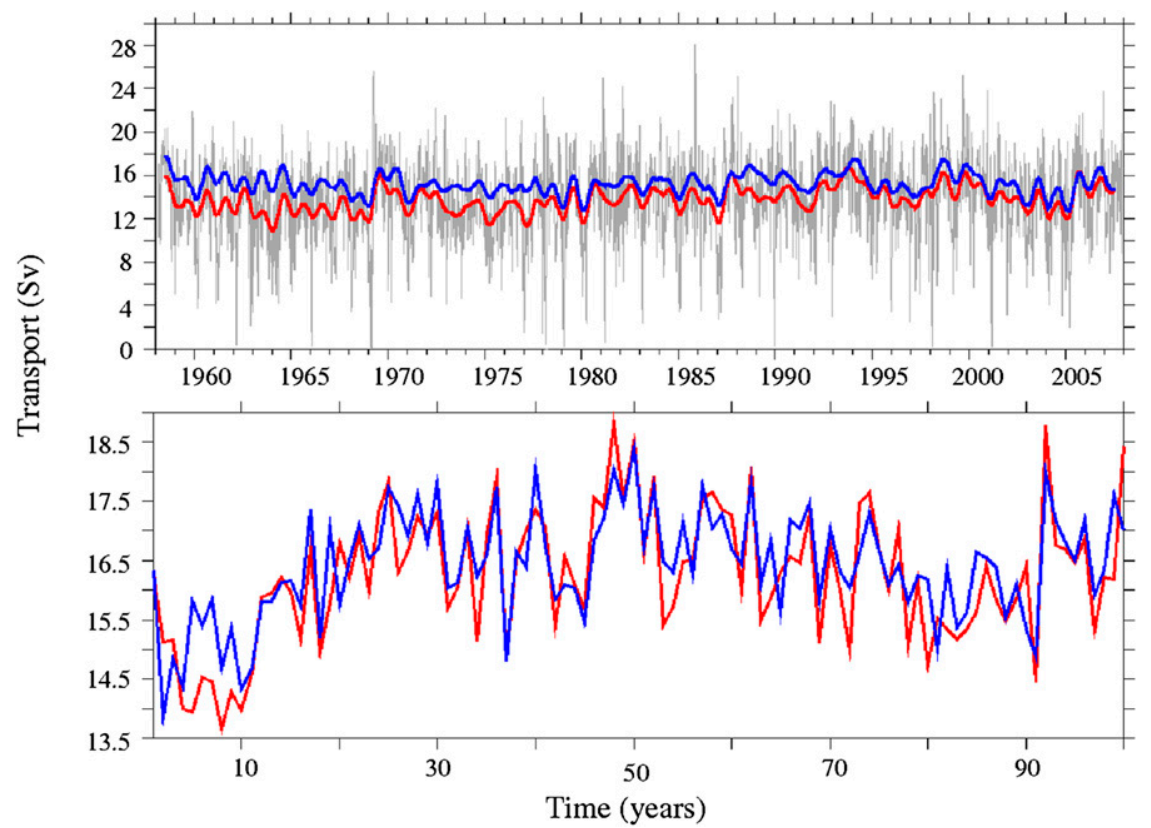

FIG. 1. AMOC in the (top) forced and (bottom) coupled simulation. For the forced simulation, the gray line represents 5-day means, and the red and the blue lines represent 1-yr smoothed data. For the coupled run, both lines represent annual means. This figure also compares two ways of computing the AMOC using model output: as a full integral of the meridional velocities (in blue) and as in the RAPID observations (in red for 1-yr smoothed data and in gray for 5-day means), summing the Ekman transport, UMO transport (defined by the zonal density gradients across the model basin), and Florida Straits transport.

pumping, generates vertical motions in the upper layers of the ocean [up to a vertical level called the level of no motion (LNM)], which produces isopycnal displacements in these layers, therefore influencing the thermohaline properties of the ocean (Gill 1982; Sturges and Hong 1995; Sinha et al. 2012).

Furthermore, in wind-driven ocean circulation theory, the southward recirculation of waters in the upper $1000 \mathrm{~m}$ of the midocean section is related to the geostrophic Sverdrup transport estimated from the wind stress curl. Wunsch (2011) showed that, over much of the subtropical and lower-latitude ocean, the Sverdrup balance appears to provide a quantitatively useful estimate of the meridional transport (about $40 \%$ of the oceanic area). The Sverdrup balance attempts to represent the meridional mass or volume transports employing only the local wind stress in a linear dynamical framework.

In this paper, the UMO transport is thus approximated by the geostrophic Sverdrup transport at $26.5^{\circ} \mathrm{N}$.

\section{2) Estimation of THE GeOstrophic SVERDRUP TRANSPORT}

The geostrophic Sverdrup component $\left(V_{g}\right.$, a meridional transport per meter depth) represents the local contribution to the southward flow that contributes to the compensation of the northward Florida Straits transport. Assuming the Sverdrup balance, $V_{g}$ is defined as

$$
V_{g}=\frac{f}{\beta} \mathbf{k} \cdot \nabla \times\left(\frac{\tau}{\rho f}\right)
$$

where $f$ is the Coriolis parameter, $\mathbf{k}$ is the unit vector in the vertical dimension, $\beta=\partial f / \partial y$ is the meridional gradient of the Coriolis parameter, $\tau$ is the wind stress, and $\rho$ is the density of seawater.

Note that $V_{g}$ can also be written as the difference between the Sverdrup component $\left(V_{\mathrm{SV}}\right)$ and the Ekman component $\left(V_{\mathrm{EKM}}\right)$ :

$$
\begin{aligned}
& V_{g}=V_{\mathrm{SV}}-V_{\mathrm{EKM}}, \\
& \text { with } \quad V_{\mathrm{EKM}}=-\frac{\tau_{x}}{\rho f}, \quad v_{\mathrm{EKM}}=-\frac{\tau_{x}}{\rho f D_{\mathrm{EKM}}}, \quad \text { and } \quad V_{\mathrm{SV}}=\frac{1}{\rho \beta} \mathbf{k} \cdot \nabla \times \boldsymbol{\tau},
\end{aligned}
$$


where $v_{\mathrm{EKM}}$ is the corresponding Ekman velocity and $D_{\text {EKM }}(=100 \mathrm{~m})$ is the depth of the Ekman layer. More details about the calculation of the Sverdrup balance can be found in the appendix at the end of this paper.

The Sverdrup transport is computed as the zonal integral of the wind stress curl between the western and eastern boundary of the array (Sverdrup 1947):

$$
T_{\mathrm{SV}}=\frac{1}{\rho \beta} \int_{x_{e}}^{x_{w}} \mathbf{k} \cdot \nabla \times \boldsymbol{\tau} d x,
$$

where $x_{e}$ corresponds to the longitude of the African coast at $26^{\circ} \mathrm{N}$ and $x_{w}$ the longitude of the Bahamian island at this same latitude.

Sverdrup theory is expected to apply only down to the LNM (Thomas et al. 2012; Wunsch 2011). Wunsch (2011) has defined this LNM as the depth where the absolute vertical velocity reaches its minimum value and shows an LNM located around $1000 \mathrm{~m}$ at $26^{\circ} \mathrm{N}$. To partially suppress the grid-scale noise in the vertical velocity, a $5^{\circ}$ of latitude and longitude spatial average was used in his calculations. Using Wunsch's criteria but focusing on the $26^{\circ} \mathrm{N}$ section, the same study has been performed using the $1 / 4^{\circ}$ simulation used in this paper and without doing any spatial smoothing (not shown in this paper). The first depth at which the vertical velocity equals $10^{-8} \mathrm{~m} \mathrm{~s}^{-1}$ has then been calculated for the North Atlantic, as well as a vertical profile of vertical velocities at $26^{\circ} \mathrm{N}$. Focusing on the vertical profile, a first shallow LNM located around $800 \mathrm{~m}$ was found as well as a second deeper level located around $1300 \mathrm{~m}$ depth. The study over the North Atlantic highlighted a lot of spatial variability in the vertical velocity field and no uniform depth was found for such an LNM over this specific area.

This method is thus not precise enough to be applied to a restricted area (like the latitude $26^{\circ} \mathrm{N}$ ); a new method has therefore been developed in this paper.

For each time step, Eq. (3) provides us with a unique value for the Sverdrup transport that is independent of depth. To be able to apply this transport down to a chosen LNM, we define a vertically structured Sverdrup transport. To do so, the original Sverdrup transport $\left(T_{\mathrm{SV}}\right)$ is divided by the area of the section delimited by the surface and the LNM to obtain a uniform velocity $\left(v_{\mathrm{SV}}\right)$ from the surface to the LNM. This area is called $A$ in Eq. (4),

$v_{\mathrm{SV}}= \begin{cases}T_{\mathrm{SV}} / A, & z \leq \mathrm{LNM}, \quad \text { with } \quad A=\int_{z=0}^{\mathrm{LNM}} \int_{x_{e}}^{x_{w}} d x d z \\ 0, & z>\mathrm{LNM} .\end{cases}$

This uniform velocity is then transformed into a transport after multiplying it by the area of each level until the
LNM $[a$ in Eq. (5), and $k$ represents the depth of the vertical level]:

$$
\begin{aligned}
T_{\mathrm{SV}}^{\prime}(z) & =v_{\mathrm{SV}} a(z), \quad z \leq \mathrm{LNM} \text { and } \\
a(z) & =\int_{x_{e}}^{x_{w}} d x \int_{k}^{k+1} d z .
\end{aligned}
$$

Then $T_{\mathrm{SV}}^{\prime}(z)$ is vertically summed [Eq. (6)] from the bottom to the surface to get a cumulative transport

$$
T_{\mathrm{SV}}(z)=\sum_{\text {bottom }}^{z} T_{\mathrm{SV}}^{\prime}(z)
$$

This cumulative transport is thus decreasing from the surface (where it is maximal) to the LNM; it is then set to zero from the LNM to the bottom of the ocean.

\section{3) Definition of THE AMOC $_{S V}$}

We now define a new AMOC index (called $\mathrm{AMOC}_{\mathrm{SV}}$ ) where the UMO transport is replaced by the geostrophic Sverdrup transport $\left[V_{g}\right.$ in Eqs. (2) and (A11) in the appendix]. The AMOC ${ }_{S V}$ is the sum of the northward Florida Straits flow plus the northward wind-driven Ekman transport in the surface layer plus the southward geostrophic Sverdrup transport in the thermocline of the midocean section (Fig. 2). It is expected to reflect variations in the AMOC only on interannual time scales because changes in wind stress curl take time to propagate their effects across the basin (Wunsch 2011).

The sum of the Florida Straits, Ekman, and geostrophic Sverdrup transports is not zero. We therefore impose the constraint that there should be no net mass transport across the section. This is achieved by imposing a timevarying barotropic compensation across the $26^{\circ} \mathrm{N}$ section (excluding the Florida Straits). The use of such a constraint is thus equivalent to having a nontemporally constant LNM. This barotropic compensation is applied to each component of the AMOC as described in Hirschi et al. (2007). Equation (7) shows the calculation of this compensation for the geostrophic Sverdrup transport,

$$
\left\{\begin{array}{l}
v_{\text {comp }}^{g}=T_{g} / A_{\text {basin }}, \\
A_{\text {basin }}=\int_{\text {bottom }}^{0} \int_{x_{e}}^{x_{w}} d x d z \\
T_{\text {comp }}^{g}(z)=v_{\text {comp }}^{g} a(z), \quad 0 \leq z \leq \text { bottom }
\end{array}\right.
$$

The barotropic compensation for the geostrophic Sverdrup transport ( $T_{\text {comp }}^{g}$ ) is applied from the surface to the bottom. It is computed by dividing the geostrophic Sverdrup transport $\left(T_{g}\right)$ by the area of the section at $26.5^{\circ} \mathrm{N}$ ( $A_{\text {basin }}$ ) to get a uniform velocity through the section $\left(v_{\text {comp }}^{g}\right)$. This velocity is then multiplied by the area of each level [called $a$ in Eq. (5)] to 


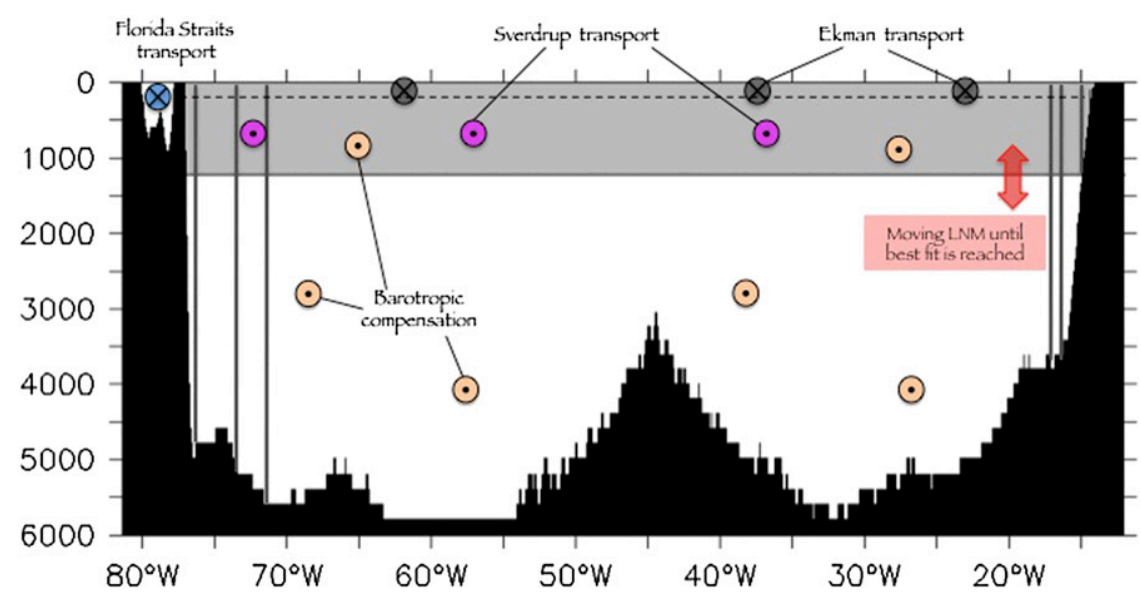

FIG. 2. Schematic of the $\mathrm{AMOC}_{\mathrm{SV}}$. On this vertical section of $26.5^{\circ} \mathrm{N}$, the Florida Straits transport is represented by a blue circle (with a cross inside, indicating its northward direction), the northward wind-driven Ekman transport is represented with green circles (with crosses inside), the barotropic compensation is represented with orange circles (with dots inside indicating its southward direction), and the geostrophic Sverdrup transport is represented with pink circles (also with dots inside). The level of no motion applied to the geostrophic Sverdrup transport is represented by a horizontal black line at around $1300 \mathrm{~m}$ on this graphic. It is calculated so that the geostrophic Sverdrup transport is in best agreement with the upper midocean (UMO) transport calculated by the RAPID array. Western and eastern boundary moorings of the RAPID array are represented by vertical lines on this graphic. The Ekman transport flows from the surface to $100 \mathrm{~m}$, the 100 -m depth being represented by a dashed line. The geostrophic Sverdrup transport flows from the surface to the level of no motion, and the barotropic compensation is applied from the surface to the bottom of the ocean.

return the compensation to $\mathrm{m}^{3} \mathrm{~s}^{-1}\left(T_{\text {comp }}^{g}\right)$. This southward barotropic compensation of the geostrophic Sverdrup transport is thus equal to zero at the bottom and maximal at the surface.

If $v^{\prime}$ represents the $\mathrm{AMOC}_{\mathrm{SV}}$ and $v$ the $\mathrm{AMOC}$ calculated as in RAPID, then

$$
v^{\prime}=v_{\mathrm{FST}}+v_{\mathrm{EKM}}+v_{g}+v_{\mathrm{comp}}^{\prime}
$$

with

$$
\begin{aligned}
v_{\mathrm{comp}}^{\prime} & =\left(v_{\mathrm{comp}}^{\mathrm{EKM}}+v_{\mathrm{comp}}^{\mathrm{FST}}+v_{\mathrm{comp}}^{g}\right) \quad \text { and } \\
v & =v_{\mathrm{FST}}+v_{\mathrm{EKM}}+v_{\mathrm{UMO}}+v_{\mathrm{comp}}
\end{aligned}
$$

with

$$
v_{\text {comp }}=\left(v_{\text {comp }}^{\mathrm{EKM}}+v_{\text {comp }}^{\mathrm{FST}}+v_{\text {comp }}^{\mathrm{UMO}}\right) \text {, }
$$

where $v_{\mathrm{FST}}$ are the meridional velocities in the Florida Straits, $v_{\text {EKM }}$ are the Ekman velocities [Eq. (2)], $v_{g}$ are the velocities associated with the geostrophic Sverdrup transport, and $v_{\mathrm{UMO}}$ are the velocities associated with the upper midocean transport,

$$
\begin{aligned}
v_{\text {geo }} & =-\frac{g}{\rho f} \int_{\text {bottom }}^{z} \frac{\partial \rho}{\partial x} d z \text { and } \\
v_{\mathrm{UMO}} & =v_{\text {geo }}(z), \quad z=0 \text { to } 1000 \mathrm{~m},
\end{aligned}
$$

with $v_{\text {geo }}$ representing the midocean geostrophic velocities. Finally, $v_{\text {comp }}$ and $v_{\text {comp }}^{\prime}$ represent the velocities associated with the barotropic compensations for the $\mathrm{AMOC}$ and $\mathrm{AMOC}_{\mathrm{SV}}$.

The AMOC transport $\psi(y, z, t)$ and the $\mathrm{AMOC}_{\mathrm{SV}}$ $\psi^{\prime}(y, z, t)$ are calculated as follows:

$$
\begin{aligned}
\psi(z, t) & =\int_{z}^{0} \int_{x_{e}}^{x_{w}} v d x d z \quad \text { and } \\
\psi^{\prime}(z, t) & =\int_{z}^{0} \int_{x_{e}}^{x_{w}} v^{\prime} d x d z,
\end{aligned}
$$

where $v$ and $v^{\prime}$ are defined in Eq. (8). The AMOC and the $\mathrm{AMOC}_{\mathrm{SV}}$ are defined at $1000 \mathrm{~m}$, close to the maximum of these streamfunctions. However, defining the AMOC at $1000 \mathrm{~m}$ or at the depth where the streamfunction reaches its maximum (as it is done using the RAPID method; Kanzow et al. 2010) does not make a lot of difference on the final transport. Indeed, the AMOC (defined as the maximum of the overturning streamfunction) is $0.2 \mathrm{~Sv}$ stronger than the AMOC defined as the sum of the transports at $1000 \mathrm{~m}$. The standard deviation of the difference is $0.2 \mathrm{~Sv}$ also (these are computed on 10-day values). 


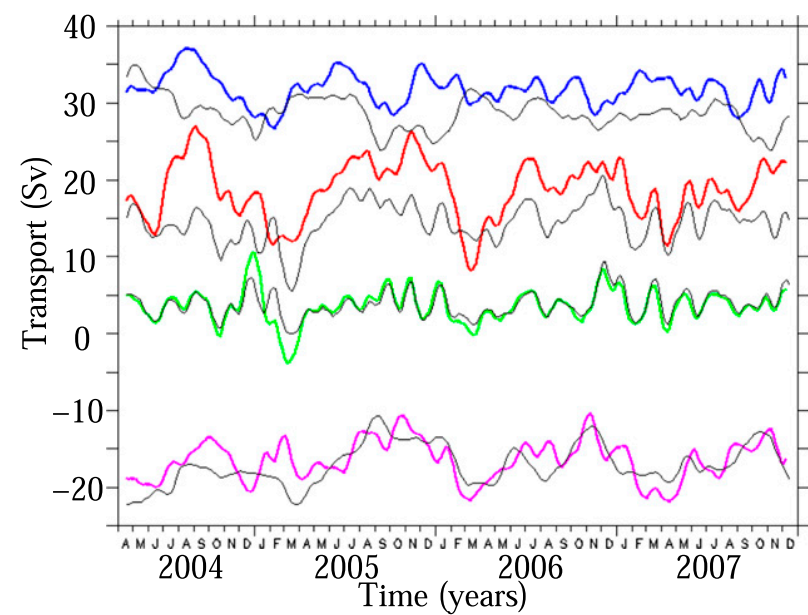

FIG. 3. The AMOC and its components in the forced simulation (in black) and in RAPID observations (colors) at $26.5^{\circ} \mathrm{N}$. 35-day smoothed data are represented in this figure. For the observations, the AMOC is represented in red, the FST in blue, the EKM in green, and the UMO transport in pink.

The $\mathrm{AMOC}_{\mathrm{SV}}$ is defined such that $\overline{\psi_{1000}}-\overline{\psi_{1000}^{\prime}}=0$ (where $\bar{\psi}$ denotes the time mean of $\psi$ ), which is equivalent to

$$
\int_{z}^{0} \int_{x_{e}}^{x_{w}} v_{\mathrm{UMO}} d x d z=\int_{z}^{0} \int_{x_{e}}^{x_{w}} v_{g} d x d z .
$$

Equation (11) can be satisfied by adjusting the LNM chosen for the geostrophic Sverdrup transport. To test the reliability of the $\mathrm{AMOC}_{\mathrm{SV}}$ at interannual and longer time scales, sensitivity studies were performed in the two NEMO simulations previously described to define the most accurate LNM for the geostrophic Sverdrup transport. The aim of these sensitivity studies is to compute the geostrophic Sverdrup transport with an LNM varying from the surface to the bottom of the ocean (testing each vertical level of the model) and assess for which level the geostrophic Sverdrup transport is in best agreement with the UMO transport. More details about these tests will be provided in section $3 b(1)$.

In section 3 , the $\mathrm{AMOC}_{\mathrm{SV}}$ thereby obtained is assessed and compared to the AMOC transport at different time scales for each simulation. As these simulations are 50 and 100 years long respectively, they allow us to assess the multidecadal variability of the $\mathrm{AMOC}_{\mathrm{SV}}$ and AMOC transport and thus to test if these transports have important long-term trends and if the $\mathrm{AMOC}_{\mathrm{SV}}$ can capture the variability and trends of the AMOC.

In the following sections, geostrophic Sverdrup transport (GST) will refer to the compensated geostrophic Sverdrup transport described above. This transport thus does not include the Ekman transport.
TABLE 1. Mean (Sv) and standard deviation of the AMOC and its components for the forced simulation and the RAPID observations for the period 2 April 2004-31 December 2007, using 35-day smoothed data. Column 4 shows the difference between the mean value of the transports in RAPID and NEMO.

\begin{tabular}{lrrcc}
\hline \hline & & & & $\begin{array}{c}\text { Correlation } \\
\text { NEMO/ }\end{array}$ \\
& \multicolumn{1}{c}{ NEMO } & \multicolumn{1}{c}{ RAPID } & Difference & RAPID \\
\hline AMOC & $14.49 \pm 2.55$ & $18.69 \pm 3.84$ & 4.2 & 0.64 \\
FST & $28.7 \pm 2.15$ & $31.77 \pm 2.04$ & 3.07 & 0.23 \\
EKM & $3.78 \pm 1.68$ & $3.49 \pm 2.15$ & -0.29 & 0.87 \\
UMO & $-17.08 \pm 2.64$ & $-16.53 \pm 2.62$ & 0.55 & 0.65 \\
\hline
\end{tabular}

\section{Results}

\section{a. Comparison of models and observations}

The 50-yr forced simulation ran from 1958 to 2007. Several successful validations of the ORCA025 configuration used to run this simulation have been made. For example, very similar simulations to the one used in this paper (only the atmospheric forcing changes between these simulations) were used by Blaker et al. (2012) and Penduff et al. (2010) [technical descriptions of this last simulation can be found in Dussin et al. (2009)] and more details about these simulations are given in these papers.

Figure 3 shows good agreement between the AMOC and its components in RAPID observations and in the NEMO simulation from 2004 to 2007. Using the model simulations, the geostrophic contribution is inferred from zonal density gradients and the thermal wind relation (Hirschi et al. 2003). The full density section rather than boundary densities are used in the calculation, but Hirschi and Marotzke (2007) have shown that this makes minimal difference to the calculated geostrophic flow. Vertical average velocity is then calculated and removed to get vertical shear. The result is then integrated zonally and vertically. The UMO transport is defined as the geostrophic flow in the upper $1000 \mathrm{~m}$.

Using 35-day smoothed data (as in Fig. 3), a correlation between the two datasets of 0.64 is found for the AMOC and 0.65 , for example, for the UMO transport. Table 1 compares the means and standard deviations of the AMOC and its components in the forced simulation and in RAPID. The mean values and standard deviations of the different transports are generally higher in RAPID observations. The biggest difference is for the FST, where observed values are $3.07 \mathrm{~Sv}$ higher than the FST in the NEMO simulation. This difference might be due to the resolution of the configuration used. Indeed, the FST is fairly coarsely represented even at $1 / 4^{\circ}$ resolution. The good fit that we find between the observed and simulated Ekman transport 
TABLE 2. Means and standard deviations of the geostrophic Sverdrup transport and the UMO transport at 1000-m depth in the two NEMO simulations. The mean values and standard deviations of the geostrophic Sverdrup transport have been computed for different levels of no motion shown in the second column of the table. The levels are expressed in meters. The means and standard deviations are expressed in Sverdrups. Different temporal scales are represented on this table: 5-day means and 1-, 5-, and 10-yr smoothed data.

\begin{tabular}{|c|c|c|c|c|c|c|}
\hline \multirow[b]{2}{*}{ Transports } & \multirow[b]{2}{*}{ LNM } & \multirow[b]{2}{*}{ Mean } & \multicolumn{4}{|c|}{ Standard deviation } \\
\hline & & & 5-day means & 1-yr smoothing & 5-yr smoothing & 10-yr smoothing \\
\hline \multicolumn{7}{|l|}{ Forced run } \\
\hline \multirow[t]{6}{*}{ Geostrophic Sverdrup } & 1000 & -16.33 & 11.85 & 2.43 & 0.99 & 0.66 \\
\hline & 1266 & -12.75 & 9.25 & 1.89 & 0.77 & 0.52 \\
\hline & 1387 & -11.25 & 8.16 & 1.67 & 0.68 & 0.45 \\
\hline & 1516 & -9.93 & 7.2 & 1.47 & 0.6 & 0.40 \\
\hline & 2101 & -5.94 & 4.31 & 0.88 & 0.36 & 0.24 \\
\hline & 3138 & -2.51 & 1.82 & 0.37 & 0.15 & 0.10 \\
\hline UMO & - & -12.73 & 2.47 & 1.44 & 0.99 & 0.78 \\
\hline \multicolumn{7}{|l|}{ Coupled run } \\
\hline \multirow[t]{6}{*}{ Geostrophic Sverdrup } & 1000 & -17.08 & - & 1.74 & 0.91 & 0.61 \\
\hline & 1266 & -13.33 & - & 1.36 & 0.71 & 0.48 \\
\hline & 1387 & -11.77 & - & 1.19 & 0.62 & 0.42 \\
\hline & 1516 & -10.38 & - & 1.06 & 0.55 & 0.37 \\
\hline & 2101 & -6.22 & - & 0.63 & 0.33 & 0.22 \\
\hline & 3138 & -2.63 & - & 0.27 & 0.14 & 0.09 \\
\hline UMO & - & -11.48 & - & 1.21 & 0.79 & 0.63 \\
\hline
\end{tabular}

highlights the confidence in the wind forcing since it is this component on which the GST is based. Finally, the mean value of the AMOC in the forced simulation is $4.2 \mathrm{~Sv}$ lower in NEMO than in the observations for the period April 2004-December 2007.

\section{b. Assessment of the $A M O C_{S V}$}

In the model experiments, Ekman and Florida Straits transports are common to both $\mathrm{AMOC}_{\mathrm{SV}}$ and the AMOC transport. The differences between the $\mathrm{AMOC}_{\mathrm{SV}}$ and the AMOC transport are thus due to the differences between the GST and the UMO transport.

\section{1) Means and standard deViations OF THE GEOSTROPHIC SVERDRUP AND UMO TRANSPORTS}

To assess the $\mathrm{AMOC}_{\mathrm{SV}}$, the GST and UMO transport are compared at different time scales. Table 2 compares the means and standard deviations of these transports for the two NEMO simulations. The depth specified in the second column indicates the LNM used for the GST. This table thus shows the sensitivity of the GST to the LNM.

We thus define this LNM as the level where the GST is in best agreement with the UMO transport. In the forced simulation, the closest mean value of GST compared to the UMO transport mean value is reached for an LNM of $1266 \mathrm{~m}$. The standard deviations of the GST and the UMO transport become comparable on time scales longer than one year. Better agreement on longer time scales is not surprising as the Sverdrup theory is expected to be valid at interannual time scales and longer (Wunsch 2011). The variability for the GST is 4 times larger than for the UMO transport if we compare 5-day means (Table 2). To have a GST for which the variability best corresponds to the variability of the UMO transport, a deeper LNM would need to be considered. Using 5-day means, an LNM around $2766 \mathrm{~m}$ results in a good match between the standard deviations of these two transports (however, the agreement between the time mean values obviously deteriorates). This LNM can be reduced to $1516 \mathrm{~m}$ when using 1-yr smoothed data with a standard deviation of $1.47 \mathrm{~Sv}$ for the GST compared to $1.44 \mathrm{~Sv}$ for the UMO transport. These results are in agreement with Thomas et al. (2012), who found an LNM at $1500 \mathrm{~m}$ in the North Atlantic.

In the coupled run, the LNM applied to the GST (chosen so that the variability and mean value of the GST are in best agreement with the UMO transport) is located at $1387 \mathrm{~m}$ (Table 2). Using this level, the mean values of these transports differ by less than $0.3 \mathrm{~Sv}$ and using annual means, their standard deviations have a difference of $0.02 \mathrm{~Sv}$.

Despite using different atmospheric forcings, a similar LNM around $1300 \mathrm{~m}$ is found in the two simulations. In the following sections, the LNM for the GST will be taken at $1266 \mathrm{~m}$ for the forced simulation and at $1387 \mathrm{~m}$ for the coupled simulation.

\section{2) VARIABILITY OF THE GEOSTROPHIC SVERDRUP AND UMO TRANSPORTS}

The upper panel of Fig. 4 compares the time series of the GST and UMO transport in the forced 

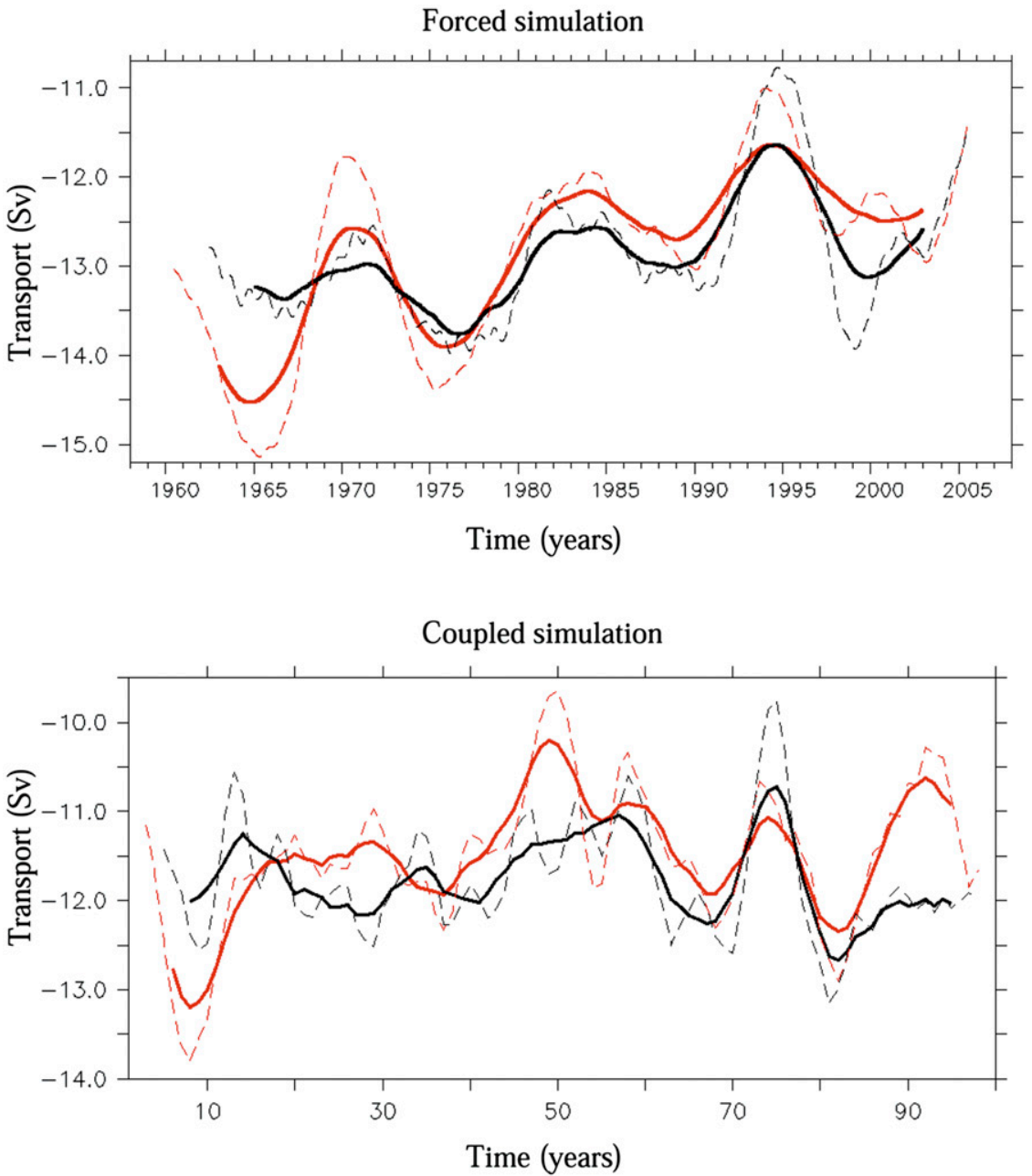

FIG. 4. Comparison between the geostrophic Sverdrup transport in black and the UMO transport in red: (top) the forced simulation (an LNM at $1266 \mathrm{~m}$ is used for the computation of the geostrophic Sverdrup transport) and (bottom) 100 years of the coupled simulation (an LNM at $1387 \mathrm{~m}$ is used for the computation of the geostrophic Sverdrup transport). Both transports are plotted at 1000-m depth. The thick lines represent 10-yr smoothed data; the thin dashed lines represent 5-yr smoothed data. For both plots, the geostrophic Sverdrup transport is represented with a lag of $-2 \mathrm{yr}$.

simulation. Cross-correlation calculations show that the maximal correlation between these two transports is reached for a lag of -750 days (approximately $-2 \mathrm{yr}$ ) applied to the GST. Indeed, the midocean response to wind stress curl (WSC) is a lagged response mediated by baroclinic Rossby waves at interannual time scales (Sinha et al. 2012). At $26^{\circ} \mathrm{N}$, Rossby waves take approximately 5 years to cross the basin (DiNezio et al. 2009). However, as wind perturbations are likely to happen at any longitude of this section, the 2-yr lag represents the average time for any anomaly induced by the WSC at the surface to propagate zonally (through Rossby waves) and vertically (though pumping) and modify the position of the isopycnals in the deeper layers of the ocean. If such a lag is applied to the GST, these two transports are significantly correlated at low frequencies with a correlation of 0.86 (Table 4 ) for 10-yr smoothed data (thick black line on Fig. 4) and 0.72 using 5-yr smoothed data (dashed lines). This lagged correlation shows that the GST precedes the UMO transport by about 2 years.

In the coupled simulation (lower panel of Fig. 4) the highest correlations between these two transports are also found when a lag of -2 years is applied to the GST. The following correlations are thus all calculated considering the GST with a lag of $-2 \mathrm{yr}$. Using the last $50 \mathrm{yr}$ of this simulation, the correlation between the UMO transport and GST is 0.59 using 10 -yr smoothed 
TABLE 3. Means and standard deviations of the $\mathrm{AMOC}_{\mathrm{SV}}$ and the AMOC transport at 1000-m depth in the two NEMO simulations. The mean values and standard deviations of the $\mathrm{AMOC}_{\mathrm{SV}}$ have been computed for different levels of no motion applied to the geostrophic Sverdrup transport which are shown in the second column of the table. The levels are expressed in meters. The means and standard deviations are expressed in Sverdrups. Different temporal scales are represented on this table: 5-day means and 1-, 5-, and 10-yr smoothed data.

\begin{tabular}{|c|c|c|c|c|c|c|}
\hline \multirow[b]{2}{*}{ Transports } & \multirow[b]{2}{*}{ LNM } & \multirow[b]{2}{*}{ Mean } & \multicolumn{4}{|c|}{ Standard deviation } \\
\hline & & & 5-day means & 1-yr smoothing & 5-yr smoothing & 10-yr smoothing \\
\hline \multicolumn{7}{|l|}{ Forced run } \\
\hline \multirow[t]{6}{*}{$\mathrm{AMOC}_{\mathrm{SV}}$} & 1000 & 10.07 & 12.1 & 2.4 & 0.73 & 0.57 \\
\hline & 1266 & 13.66 & 9.63 & 1.91 & 0.57 & 0.45 \\
\hline & 1387 & 15.16 & 8.62 & 1.72 & 0.52 & 0.39 \\
\hline & 1516 & 16.49 & 7.74 & 1.55 & 0.47 & 0.36 \\
\hline & 2101 & 20.49 & 5.29 & 1.12 & 0.41 & 0.27 \\
\hline & 3138 & 23.93 & 3.71 & 0.91 & 0.46 & 0.25 \\
\hline AMOC & - & 13.70 & 3.69 & 1.15 & 0.70 & 0.61 \\
\hline \multicolumn{7}{|l|}{ Coupled run } \\
\hline \multirow[t]{6}{*}{$\mathrm{AMOC}_{\mathrm{SV}}$} & 1000 & 10.64 & - & 1.91 & 0.95 & 0.65 \\
\hline & 1266 & 14.39 & - & 1.58 & 0.78 & 0.54 \\
\hline & 1387 & 15.96 & - & 1.44 & 0.71 & 0.49 \\
\hline & 1516 & 17.34 & - & 1.33 & 0.65 & 0.46 \\
\hline & 2101 & 21.51 & - & 1.04 & 0.51 & 0.37 \\
\hline & 3138 & 25.1 & - & 0.88 & 0.44 & 0.33 \\
\hline AMOC & - & 16.22 & - & 1.11 & 0.82 & 0.67 \\
\hline
\end{tabular}

data and 0.61 using 5-yr smoothed data (Table 4). These correlations decrease to 0.44 (thick lines) using 10 -yr smoothed data and 0.42 using 5 -yr smoothed data (dashed lines) when the full 100-yr time series is used. These lower correlations (compared to the forced simulation) are due to the initial stage of spinup covering almost the first $20-30 \mathrm{yr}$ of the coupled simulation (Fig. 1). During these first years, the GST does not seem to be a good approximation of the UMO transport. Indeed, during this initial stage of the simulation, we expect a progressive adjustment of the densities. This adjustment can only appear in the UMO transport and not the GST.

\section{c. Simulated interannual to decadal variability in the $A M O C$ and the $A M O C_{S V}$}

The $\mathrm{AMOC}_{\mathrm{SV}}$ is defined as the sum of the FST, the Ekman transport, and the GST. Table 3 compares the means and standard deviations of this index with the AMOC transport. These values are shown at $1000 \mathrm{~m}$.
The GST used to compute the $\mathrm{AMOC}_{\mathrm{SV}}$ is calculated with a lag of -2 yr. As for Fig. 4 and Table 2, a good agreement is found between the $\mathrm{AMOC}_{\mathrm{SV}}$ and the AMOC transport if an LNM of $1266 \mathrm{~m}$ is used for the GST in the forced simulation and $1387 \mathrm{~m}$ for the coupled simulation. For both simulations, the mean value of the $\mathrm{AMOC}_{\mathrm{SV}}$ increases if a deeper LNM is chosen, and its variability increases as the LNM becomes shallower.

Several methods can be used to compute the AMOC using model output. The AMOC can be readily computed by integrating the full meridional velocity field; it can also be computed as the sum of the Ekman transport, FST, and the UMO transport derived from density gradients. This latter method is the one used to compute the AMOC using RAPID observations. Here, we apply the latter method to the models, for a more direct comparison between RAPID and the model results. The two methods give similar results as shown in Fig. 1. In the forced simulation, the correlation between the AMOC and the $\mathrm{AMOC}_{\mathrm{SV}}$ is 0.76 (Table 4) using 10-yr

TABLE 4. Correlation between the geostrophic Sverdrup transport and UMO transport (first line) and between the AMOC $\mathrm{SV}_{\mathrm{S}}$ and the AMOC (second line) for the forced and coupled runs. A -2-yr lag is applied to the geostrophic Sverdrup transport when compared to the UMO transport as well as to this transport when included in the calculation of the AMOC $\mathrm{SV}$. Correlations using 5- and 10-yr smoothed data are represented on this table. For the coupled simulation, the last 50 years of the simulation have been used to avoid to take into account the first years of spinup.

\begin{tabular}{|c|c|c|c|c|}
\hline \multirow[b]{2}{*}{ Correlations } & \multicolumn{2}{|c|}{ Forced run } & \multicolumn{2}{|c|}{ Coupled run } \\
\hline & 5-yr smoothing & 10-yr smoothing & 5-yr smoothing & 10-yr smoothing \\
\hline GST/UMO & 0.72 & 0.86 & 0.61 & 0.59 \\
\hline $\mathrm{AMOC}_{\mathrm{SV}} / \mathrm{AMOC}$ & 0.41 & 0.76 & 0.66 & 0.69 \\
\hline
\end{tabular}


Forced simulation

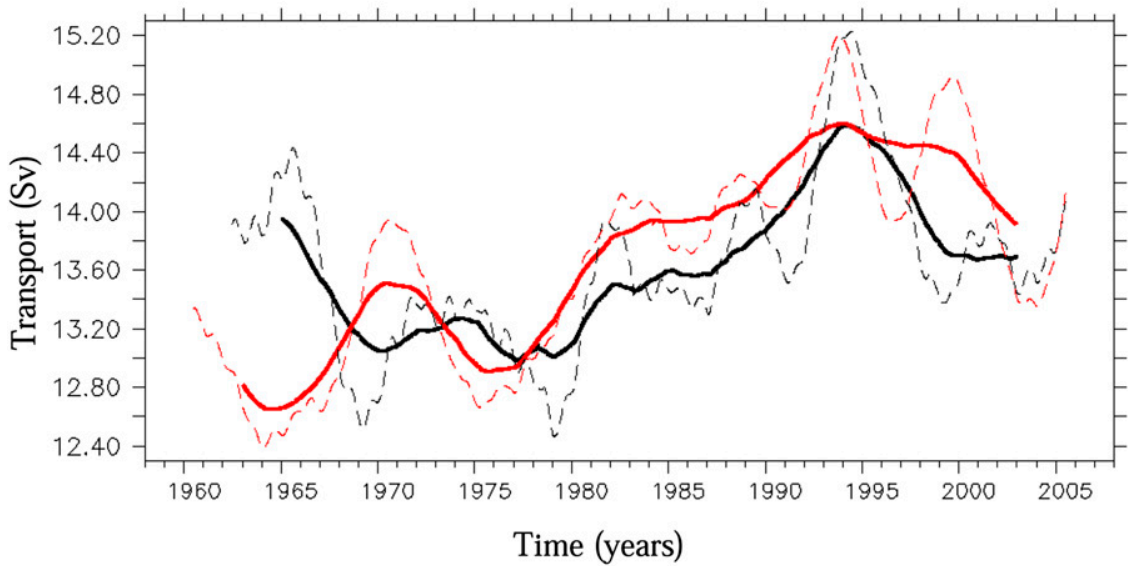

Coupled simulation

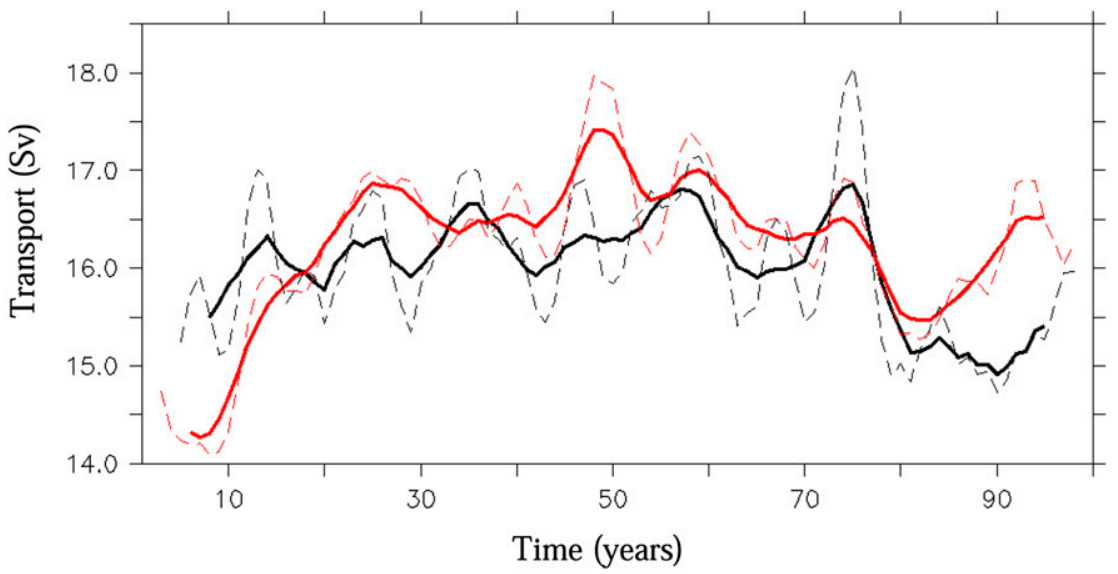

FIG. 5. Comparison between the $\mathrm{AMOC}_{\mathrm{SV}}$ (black) and the AMOC transport (red), showing the (top) forced and (bottom) coupled simulations. The thick lines represent 10-yr smoothed data; the dashed lines represent 5-yr smoothed data. In the $\mathrm{AMOC}_{\mathrm{SV}}$, the geostrophic Sverdrup transport is computed with a lag of $-2 \mathrm{yr}$.

smoothed data (thick lines in Fig. 5) and 0.41 using 5-yr smoothed data, showing good agreement between the two transports at low frequencies.

In the coupled simulation, good agreement is also found between the $\mathrm{AMOC}_{\mathrm{SV}}$ and the AMOC transport with a correlation of 0.46 between these two transports using 5 -yr smoothed data and 0.5 using 10 -yr smoothed data (lower panel of Fig. 5). As for the comparison between the GST and the UMO transport, the first 50 years of the simulation can be considered as a stage of spinup. After removing this period, these correlations increase to 0.66 using $5-\mathrm{yr}$ smoothed data and 0.69 using $10-\mathrm{yr}$ smoothed data (Table 4).

The linear trends of the $\mathrm{AMOC}_{\mathrm{SV}}$ (not shown) and the AMOC transport were computed to assess the multidecadal variability in the $\mathrm{AMOC}$ and the $\mathrm{AMOC}_{\mathrm{SV}}$ in both the forced and coupled simulation. No significant trend was found in either simulation showing that both $\mathrm{AMOC}$ and the $\mathrm{AMOC}_{\mathrm{SV}}$ are quite stable during the century simulated in these runs. However, 50 years of simulation might not be long enough to analyze any trend in these transports as the adjustment period (model spinup) for the FST, for example, is quite long. Döscher et al. (1994) showed, for example, that the adjustment to a dynamic quasi equilibrium involves Rossby waves in the interior of the ocean and is attained in about two decades within the North Atlantic.

Kanzow et al. (2010) used the first 4 years of RAPID observations to analyze the frequency spectrum of the AMOC and its components (see Fig. 8 in their paper). Figure 6 shows a spectral analysis of the AMOC, the $\mathrm{AMOC}_{\mathrm{SV}}$, and their components in the forced 


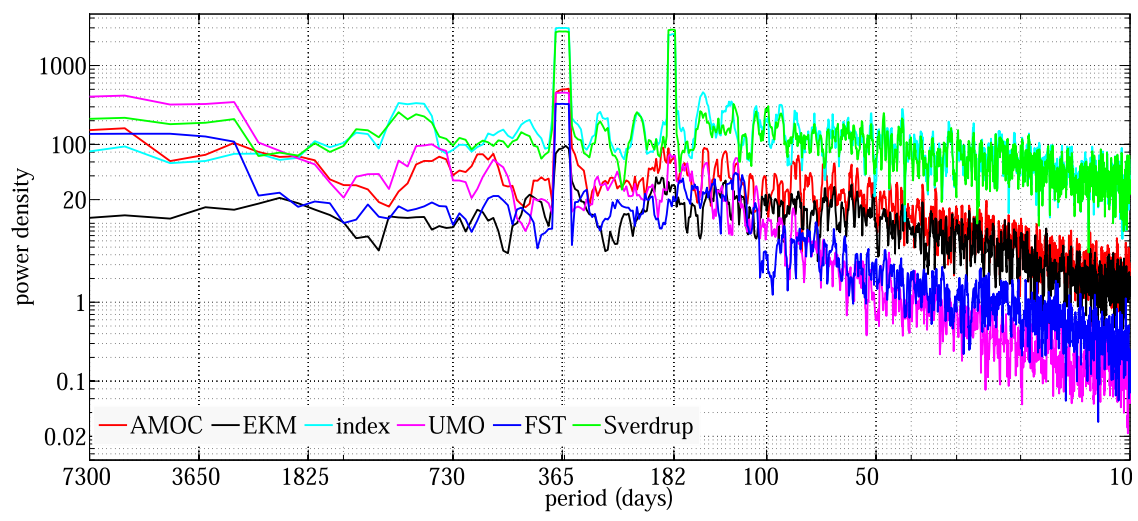

FIG. 6. Power spectrum analysis for the AMOC (red), the AMOC $\mathrm{SV}$ (cyan), and their components: the UMO transport (pink), the Ekman transport (black), the geostrophic Sverdrup transport (green), and the FST (blue) in the forced simulation.

simulation and shows similar results. For periods shorter than 100 days, the Ekman component dominates the variability of the AMOC transport. A similar peak at 200 days for the Ekman transport is found in our Fig. 6 and in Fig. 8 of Kanzow et al. (2010). The AMOC $\mathrm{SV}$ and the GST are the more energetic signals for all high frequencies shorter than $5 \mathrm{yr}$; the UMO component then clearly dominates the variability of the AMOC and all the other components. For periods longer than one year, the UMO transport and AMOC transport have very similar periodicities, as well as the GST and the $\mathrm{AMOC}_{\mathrm{SV}}$. A peak at 1 year is clearly seen for all the transports showing a clear annual cycle in these transports [in good agreement with Kanzow et al. (2010)].

Figure 7 shows a comparison between the power spectrum of the UMO transport (pink) and the GST (green) in the forced simulation. For periods longer than one year, the power spectra of the GST and UMO transports are similar. For periods shorter than one year the phases of the two transports are quite different, which further illustrates that the $\mathrm{AMOC}_{\mathrm{SV}}$ only works on interannual time scales and longer.

At subannual time scales, we note two similar peaks of energy in the GST and UMO transport, one around 6 months and a minor one around 4 months. Although these peaks are common to the two transports, they are much more energetic for the GST. The peak around 6 months is clearly seen for the GST [as shown by Atkinson et al. (2010)] and the $\operatorname{AMOC}_{\mathrm{SV}}$ (Fig. 6) although it does not appear in the AMOC transport and is less energetic in the UMO transport. As there is a lot of high-frequency variability in the UMO transport for periods shorter than 6 months, the slight peak at 6 months for this transport (mainly visible in Fig. 7)

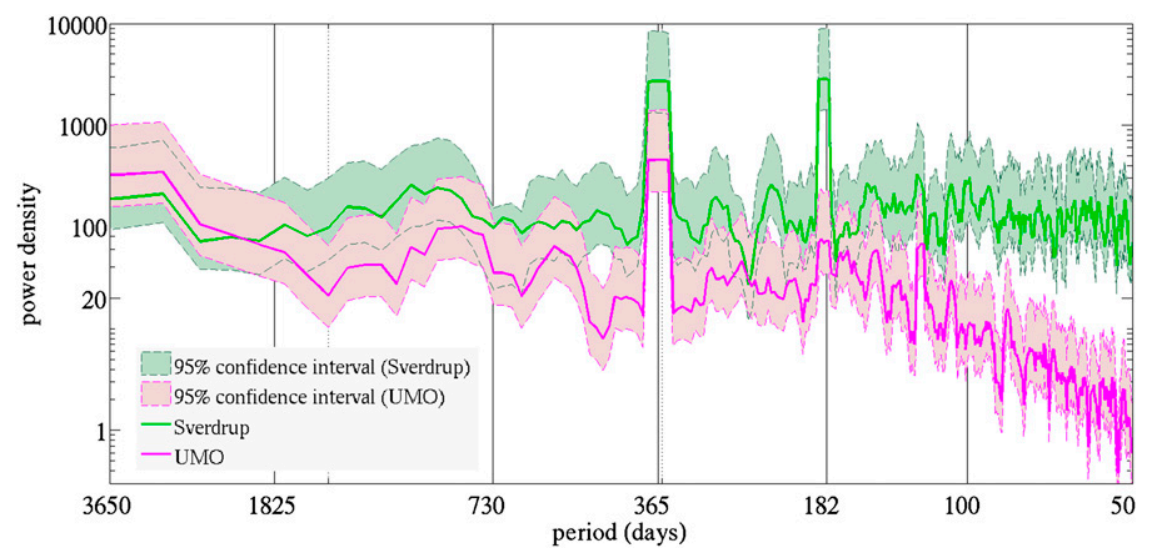

FIG. 7. Power spectrum analysis, comparison between the frequency spectrum of the UMO transport (in pink), and the geostrophic Sverdrup transport (in green) in the forced simulation. The $95 \%$ confidence intervals are also shaded in this graphic. These two spectra are identical to those presented on Fig. 6, with a zoom between day 50 and $10 \mathrm{yr}$. 
might not be significant as two other similar peaks are observed between day 100 and 6 months [no similar peak at 6 months appears in Fig. 8 of Kanzow et al. (2010)]. There is clearly more short-term variability in the GST than in the UMO transport, but we do not expect the short-term variability in the GST to show up in short-term UMO transport.

These spectral analyses show that, in addition to being significantly correlated, the GST and UMO transport have similar dominant periodicities for periods longer than one year.

\section{Discussion and conclusions}

The RAPID observations are the only observations available to assess the AMOC variability at $26.5^{\circ} \mathrm{N}$. However, these estimations of the AMOC transport only began in April 2004. Here, we have developed a new index of AMOC variability (called $\mathrm{AMOC}_{\mathrm{SV}}$ ) that could allow us to reconstruct an observation-based AMOC transport back in time to 1982 when the Florida Straits transport (FST) measurements became available. This index is the sum of the northward Florida Straits transport, the wind-driven Ekman transport, and the southward geostrophic Sverdrup transport (GST). It is based on the assumption that the upper midocean (UMO) transport can be replaced by the GST at interannual and decadal time scales.

The $\mathrm{AMOC}_{\mathrm{SV}}$ provides an estimate of the surface branch of the AMOC and cannot provide any information about deep circulation features such as the Deep Western Boundary Current (DWBC). The effect of the DWBC is, however, taken into account indirectly via the barotropic compensation, which ensures that there is no net mass transport across the section.

A forced and a coupled simulation are used to assess this $\mathrm{AMOC}_{\mathrm{SV}}$. In the forced simulation, the AMOC transport and its components are in good agreement with RAPID observations for the period 2004-07. These simulations have many similarities such as the model used (NEMO), the configuration used (ORCA025), and their horizontal and vertical resolutions. The ocean circulation in these simulations mainly differs by having an imposed (in the forced simulation) versus coupled approach (in the coupled run) to the atmospheric forcing. In the framework of this study focusing on the GST, using these two simulations is a good way to assess the $\mathrm{AMOC}_{\mathrm{SV}}$ since the GST is a function of the wind stress curl and so a function of the atmospheric forcing. The interest in using these two simulations is thus to show that this index is valid regardless of the nature of the atmospheric forcing applied.
The Sverdrup transport is computed as the zonal integral of the wind stress curl between the western and eastern boundary of the array (Sverdrup 1947). The equations of section $2 b(2)$ and the appendix show that the southward GST plus Ekman transport form the Sverdrup transport that contributes to the compensation of the northward flowing Florida Straits transport. In this study, our assumption ignores the presence of the Antilles Current flowing on the eastern side of the Bahamas as we assume that at $26^{\circ} \mathrm{N}$ most of the western boundary current flows in the Florida Straits. The Antilles Current transport ( $3.2 \mathrm{~Sv}$ ) is negligible compared to the Florida Straits transport $(31.6 \mathrm{~Sv})$ (FrajkaWilliams et al. 2013). Using both the $1 / 4^{\circ}$ forced simulation (which resolution does not allow us to represent the Antilles Current) and a $1 / 12^{\circ}$ NEMO simulation (not shown), we have found that including the Antilles Current in the index calculation or not does not have a major impact on our results although the Antilles Current is correctly represented in the $1 / 12^{\circ}$ simulation.

In our new index (the AMOC $\mathrm{SV}$ ), the GST is applied down to a depth called the level of no motion (LNM). This LNM is defined for the GST to be in best agreement with the UMO transport (in terms of mean and standard deviation) and is found to be around $1300 \mathrm{~m}$ for both the forced and coupled simulations. These results are in agreement with Thomas et al. (2012) and with the LNM found at $1300 \mathrm{~m}$ using the Wunsch (2011) method (not shown). A sensitivity study of GST to the LNM showed that the imprint of this transport on the $\mathrm{AMOC}_{\mathrm{SV}}$ is different according to the LNM chosen for the GST (Table 3). Using a LNM around $1300 \mathrm{~m}$ and comparing the GST and UMO transport at $1000 \mathrm{~m}$, these two transports are found to be in good agreement in terms of mean and variability at low frequency.

In the forced simulation, the UMO transport and GST have very similar mean values, by definition (Table 2). For the timing of these two time series to be in best agreement at interannual time scales, a lag of $-2 \mathrm{yr}$ needs to be applied to the GST, to allow any anomaly induced by the wind stress curl at the surface of the ocean to propagate zonally (through Rossby waves) and vertically (through pumping) and modify the position of the isopycnals in the deeper layers of the ocean. When such a lag is applied to the GST, this transport becomes significantly correlated with the UMO transport at low frequency.

In the coupled run, the GST and UMO transport are also in good agreement (Table 2). If the same lag of $-2 \mathrm{yr}$ is also applied to the GST, and when the spinup time of the run is removed from the time series, these two transports are significantly correlated.

These numerical simulations do not display any noticeable multidecadal trend in the $\mathrm{AMOC}_{\mathrm{SV}}$ or in the 
AMOC transport as in Matei et al. (2012). A spectral analysis of the $\mathrm{AMOC}_{\mathrm{SV}}$, the AMOC transport, and their components shows that the Ekman transport dominates the variability of the AMOC transport for periods shorter than 100 days and that the UMO transport then clearly dominates the variability of the AMOC for periods longer than $1 \mathrm{yr}$. In addition to being significantly correlated, the GST and UMO transport have similar energies for periods longer than $1 \mathrm{yr}$ with a peak around $1 \mathrm{yr}$ showing their strong annual cycle.

Previous studies showed how the wind stress curl influences the density fluctuations at the boundaries of the $26.5^{\circ} \mathrm{N}$ section. Kanzow et al. (2010), Chidichimo et al. (2010), Hirschi et al. (2007), and Duchez et al. (2014) showed that the observed seasonal cycle in the AMOC and the eastern boundary density at $26.5^{\circ} \mathrm{N}$ are driven primarily by seasonal wind stress curl variations near the eastern boundary. Matei et al. (2012) speculated that the seasonally varying wind stress curl near the eastern boundary might repeatedly imprint itself onto eastern boundary density. Consequently, we assume that knowledge of density at any given time would reflect forcing over a longer period in the past. The $\mathrm{AMOC}_{\mathrm{SV}}$ described in this paper is thus able to capture density fluctuations owing to local perturbations in the wind stress curl.

Nevertheless, the $\mathrm{AMOC}_{\mathrm{Sv}}$ might not be able to capture any anomalous density fluctuations occurring away from $26.5^{\circ} \mathrm{N}$ unless this remote density fluctuation also impacts the wind stress curl at $26.5^{\circ} \mathrm{N}$ (Heimbach et al. 2011). If we consider a global warming scenario with a density anomaly occurring in the Nordic seas, for example, this anomaly can have an impact on the AMOC at $26.5^{\circ} \mathrm{N}$ through a change in the transport of the lower limb of the AMOC. The $\mathrm{AMOC}_{\mathrm{SV}}$ will only be affected by this change in the Nordic seas if this remote density anomaly is associated with an anomaly in the atmospheric forcing in the northern latitudes or an anomaly in the Florida Straits transport, and if the atmospheric forcing (and thus the wind stress curl) at $26.5^{\circ} \mathrm{N}$ is also anomalous.

The deep midocean water masses at $26.5^{\circ} \mathrm{N}$ primarily consist of upper and lower North Atlantic Deep Water (NADW), originating from the Labrador Sea and Nordic seas, respectively. One possible scenario of AMOC collapse would be a decrease in the southward flow of these waters. McCarthy et al. (2012) showed that, during the pronounced AMOC downturn of 2009-10, the transport of these water masses showed interannual variability similar to the $\mathrm{AMOC}$ variability at $26.5^{\circ} \mathrm{N}$. This suggests that the variability of the NADW at $26.5^{\circ} \mathrm{N}$ may be more related to local conditions than variability in the formation regions, which have been relatively constant over the period of the RAPID measurements
(Hansen et al. 2010). With our new index $\left(\mathrm{AMOC}_{\mathrm{SV}}\right)$ being able to capture changes due to local wind-driven anomalies, it would thus also be able to show the AMOC event described in McCarthy et al. (2012).

The maximum value of the $\mathrm{AMOC}_{\mathrm{SV}}$ (occurring around 1995) is also in good agreement with results by Marsh et al. (2008), who used a combination of data (model hindcast, satellite SST, historical hydrographic estimates) to find decadal changes in meridional heat transport and the AMOC over 1985-2002, with a notable increase in the AMOC component of heat transport at all latitudes, from $26^{\circ} \mathrm{N}$ to the subpolar gyre, around the mid-1990s (see Fig. 14b in their paper). Here, Fig. 5 (top) also shows that the major peak in the AMOC and AMOC $_{\text {SV }}$ since 1958 occurred in the 1990s.

Using an ocean-only forced simulation and a coupled ocean-atmosphere simulation, we have shown that the $\mathrm{AMOC}_{\mathrm{SV}}$ can capture a substantial fraction of the AMOC variability and is in good agreement with the AMOC transport at $26^{\circ} \mathrm{N}$ both at interannual and decadal time scales.

We note that our new index $\left(\mathrm{AMOC}_{\mathrm{SV}}\right)$ could be applied to observations for the period from 1982 onward when observations are available for both the wind stress and the Florida Straits transport. The index would be calibrated using the RAPID AMOC observations that are available from 2004 onward. The calibration of the index will be affected by the length of the RAPID AMOC record. Our model based results suggest that the index can capture the AMOC variability on time scales of $5 \mathrm{yr}$ and longer meaning that the current length of the RAPID record ( $8 \mathrm{yr})$ may be too short for a proper calibration of the index.

Given that the main aim of this paper is to provide a proof of concept for the $\mathrm{AMOC}_{\mathrm{SV}}$, we leave the calculation and discussion of an observation-based AMOC index for a future study.

Acknowledgments. The RAPID observations of the Atlantic meridional overturning circulation are supported by the Natural Environment Research Council (NERC), the National Science Foundation, and NOAA. A. Duchez was supported by NERC and the RAPID project. C. P. Atkinson was supported by a NERC PhD studentship. M. S. Mizielinski is supported by the Joint DECC/Defra Met Office Hadley Centre Climate Programme (GA01101). The forced run was completed by B. de Cuevas at the National Oceanography Centre (Southampton, United Kingdom). The coupled simulation was run by M. S. Mizielinski from the Met Office and access to the model output was in the framework of the NERC-Met Office Joint Ocean Modelling Program and the Met Office global coupled 
model development programme (CAPTIVATE). The authors thank F. Sévellec for helpful discussions and the two anonymous reviewers as well as the editor for helpful comments on the manuscript.

\section{APPENDIX}

\section{Sverdrup Balance}

We provide here a derivation of the Sverdrup balance, showing that it is the sum of the geostrophic Sverdrup transport driven by the convergences of Ekman transport due to the curl of the wind stress and the ageostrophic Ekman transport due to the wind stress.

The equations of geostrophy are

$$
\begin{aligned}
-f v_{g} & =\frac{1}{\rho} \frac{\partial p}{\partial x} \quad \text { and } \\
f u_{g} & =\frac{1}{\rho} \frac{\partial p}{\partial y},
\end{aligned}
$$

where $u_{g}$ and $v_{g}$ are the zonal and meridional geostrophic velocities.

The continuity equation is

$$
\frac{\partial u}{\partial x}+\frac{\partial v}{\partial y}+\frac{\partial w}{\partial z}=0
$$

Cross differentiate and subtract Eqs. (A1) and (A2), using the continuity equation [Eq. (A3)] to obtain the linear vorticity equation,

$$
\begin{aligned}
\frac{\partial}{\partial y}\left(-f v_{g}\right)= & -f \frac{\partial v_{g}}{\partial y}-v_{g} \frac{\partial f}{\partial y}=\frac{1}{\rho} \frac{\partial^{2} p}{\partial y \partial x}, \\
\frac{\partial}{\partial x}\left(f u_{g}\right)= & u \frac{\partial f}{\partial \partial x}+f \frac{\partial u_{g}}{\partial x}=\frac{1}{\rho} \frac{\partial^{2} p}{\partial x \partial y}, \\
& -f \frac{\partial v_{g}}{\partial y}-v_{g} \frac{\partial f}{\partial y}-f \frac{\partial u_{g}}{\partial x}=0, \\
v_{g} \frac{\partial f}{\partial y}= & -f\left(\frac{\partial v_{g}}{\partial y}+\frac{\partial u_{g}}{\partial x}\right)=-f\left(-\frac{\partial w}{\partial z}\right), \quad \text { and } \\
\beta v_{g}= & f \frac{\partial w}{\partial z},
\end{aligned}
$$

where $\beta=\partial f / \partial y$ and $w$ is the vertical velocity. Equation (A4) is the linear vorticity equation.

Integrating Eq. (A4) from some depth $z_{0}$ to the surface $(z=0)$, one obtains

$\int_{z_{0}}^{0} \beta v_{g} d z=\int_{z_{0}}^{0} f \frac{\partial w}{\partial z} d z \Leftrightarrow \beta V_{g}=f\left[w_{0}\right]-f\left[w_{z_{0}}\right]$,

where $w_{0}=w_{E}$ is the Ekman pumping velocity.
The Ekman equations are

$$
-f v_{E}=\frac{1}{\rho} \frac{\partial \tau_{x}}{\partial z} \quad \text { and } \quad f u_{E}=\frac{1}{\rho} \frac{\partial \tau_{y}}{\partial z},
$$

which give, after vertical integration from $z_{0}$ to the surface,

$$
V_{E}=-\frac{\tau_{x}}{\rho f} \quad \text { and } \quad U_{E}=\frac{\tau_{y}}{\rho f} .
$$

Using Eq. (A3),

$$
\begin{gathered}
\frac{\partial}{\partial x} \int_{z_{0}}^{0} u d z+\frac{\partial}{\partial y} \int_{z_{0}}^{0} v d z=-\int_{z_{0}}^{0} \frac{\partial w}{\partial z} d z=-w_{z_{0}}=w_{E} \quad \text { and } \\
\frac{\partial U_{E}}{\partial x}+\frac{\partial V_{E}}{\partial y}=\frac{\partial}{\partial x}\left(\frac{\tau_{y}}{\rho f}\right)-\frac{\partial}{\partial y}\left(\frac{\tau_{x}}{\rho f}\right)=\mathbf{k} \cdot \nabla \times\left(\frac{\boldsymbol{\tau}}{\rho f}\right)=w_{E} .
\end{gathered}
$$

Now substituting Eq. (A7) into Eq. (A5) and choosing $z_{0}$ where $w\left(z_{0}\right)=0$, we get

$$
V_{g}=\frac{f}{\beta} \mathbf{k} \cdot \nabla \times\left(\frac{\tau}{\rho f}\right),
$$

which is the geostrophic transport caused by northsouth and east-west variations of the wind and the consequent convergence of Ekman mass transport. We can combine the geostrophic transport [Eq. (A8)] and the Ekman transport [Eq. (A6)] to get the total transport (Sverdrup transport):

$$
V_{s}=V_{g}+V_{E}=\frac{f}{\beta} \mathbf{k} \cdot \nabla \times\left(\frac{\boldsymbol{\tau}}{\rho f}\right)-\frac{\tau_{x}}{\rho f},
$$

which on expanding the vector cross-product gives

$$
V_{s}=\frac{f}{\beta}\left[\frac{\partial}{\partial x}\left(\frac{\tau_{y}}{\rho f}\right)-\frac{\partial}{\partial y}\left(\frac{\tau_{x}}{\rho f}\right)\right]-\frac{\tau_{x}}{\rho f},
$$

and now expanding derivatives in the usual way gives

$$
\begin{aligned}
V_{s}= & \frac{f}{\rho \beta}\left[f^{-2}\left(\frac{\partial \tau_{y}}{\partial x} f-\tau_{\not \partial \partial x} \frac{\partial f}{\partial x}\right)\right. \\
& \left.-f^{-2}\left(\frac{\partial \tau_{x}}{\partial y} f-\tau_{x} \frac{\partial f}{\partial y}\right)\right]-\frac{\tau_{x}}{\rho f},
\end{aligned}
$$

and finally, using $\partial f / \partial x=0$ and writing $\partial f / \partial y=\beta$, we get

$$
V_{s}=\frac{f}{\rho \beta}\left[\frac{1}{f} \frac{\partial \tau_{y}}{\partial x}-\frac{1}{f} \frac{\partial \tau_{x}}{\partial y}+\frac{\beta}{f^{2}} \tau_{x}\right]-\frac{\tau_{x}}{\rho f}=\frac{1}{\rho \beta}\left[\frac{\partial \tau_{y}}{\partial x}-\frac{\partial \tau_{x}}{\partial y}\right],
$$

leading to

$$
V_{s}=\frac{1}{\rho \beta} \mathbf{k} \cdot \nabla \times \boldsymbol{\tau},
$$


where Eq. (A10) is the usual Sverdrup balance.

We then conclude from Eqs. (A9) and (A10) that

$$
V_{g}=V_{s}-V_{E}=\frac{1}{\rho \beta} \mathbf{k} \cdot \nabla \times \boldsymbol{\tau}+\frac{\tau_{x}}{\rho f}=\frac{f}{\beta} \mathbf{k} \cdot \nabla \times\left(\frac{\boldsymbol{\tau}}{\rho f}\right) .
$$

\section{REFERENCES}

Atkinson, C. P., H. L. Bryden, J. J.-M. Hirschi, and T. Kanzow, 2010: On the seasonal cycles and variability of Florida Straits, Ekman and Sverdrup transports at $26^{\circ} \mathrm{N}$ in the Atlantic Ocean. Ocean Sci., 6, 837-859, doi:10.5194/os-6-837-2010.

Atlas, R., R. N. Hoffman, J. Ardizzone, S. M. Leidner, J. C. Jusem, D. K. Smith, and D. Gambos, 2011: A cross-calibrated, multiplatform ocean surface wind velocity product for meteorological and oceanographic applications. Bull. Amer. Meteor. Soc., 92, 157-174, doi:10.1175/2010BAMS2946.1.

Baringer, M. O., and J. Larsen, 2001: Sixteen years of Florida Current transport at $27^{\circ}$ N. Geophys. Res. Lett., 28, 3179-3182, doi:10.1029/2001GL013246.

Barnier, B., and Coauthors, 2006: Impact of partial steps and momentum advection schemes in a global ocean circulation model at eddy-permitting resolution. Ocean Dyn., 56, 543-567, doi:10.1007/s10236-006-0082-1.

- and Coauthors, 2007: Eddy-permitting ocean circulation hindcasts of past decades. CLIVAR Exchanges, No.42 (Vol. 12), International CLIVAR Project Office, Southampton, United Kingdom, 8-10. [Available online at http://eprints.soton.ac.uk/ 47576/01/Exch_42_Jul07.pdf.]

Biastoch, A., C. W. Böning, J. Getzlaff, J.-M. Molines, and G. Madec, 2008: Causes of interannual-decadal variability in the meridional overturning circulation of the midlatitude North Atlantic Ocean. J. Climate, 21, 6599-6615, doi:10.1175/ 2008JCLI2404.1.

Blaker, A. T., J. J.-M. Hirschi, B. Sinha, B. de Cuevas, S. Alderson, A. Coward, and G. Madec, 2012: Large near-inertial oscillations of the Atlantic meridional overturning circulation. Ocean Modell., 42, 50-56, doi:10.1016/j.ocemod.2011.11.008.

Chidichimo, M. P., T. Kanzow, S. A. Cunningham, W. E. Johns, and J. Marotzke, 2010: The contribution of eastern-boundary density variations to the Atlantic meridional overturning circulation at $26.5^{\circ}$ N. Ocean Sci., 6, 475-490, doi:10.5194/ os-6-475-2010.

Collins, M., and B. Sinha, 2003: Predictability of decadal variations in the thermohaline circulation and climate. Geophys. Res. Lett., 30, 1306, doi:10.1029/2002GL016504.

Cunningham, S. A., and Coauthors, 2007: Temporal variability of the Atlantic meridional overturning circulation at $26^{\circ} \mathrm{N}$. Science, 317, 935-938, doi:10.1126/science.1141304.

Delworth, T., S. Manabe, and R. J. Stouffer, 1993: Interdecadal variations of the thermohaline circulation in a coupled ocean-atmosphere model. J. Climate, 6, 1993-2011, doi:10.1175/ 1520-0442(1993)006<1993:IVOTTC >2.0.CO;2.

DiNezio, P. N., L. J. Gramer, W. E. Johns, C. S. Meinen, and M. O. Baringer, 2009: Observed interannual variability of the Florida Current: Wind forcing and the North Atlantic Oscillation. J. Phys. Oceanogr., 39, 721-736, doi:10.1175/ 2008JPO4001.1.

Döscher, R., C. W. Böning, and P. Herrmann, 1994: Response of circulation and heat transport in the North Atlantic to changes in thermohaline forcing in the northern latitudes: A model study. J. Phys. Oceanogr., 24, 2306-2320, doi:10.1175/ 1520-0485(1994)024<2306:ROCAHT>2.0.CO;2.

Duchez, A., E. Frajka-Williams, N. Castro, J. Hirschi, and A. Coward, 2014: Seasonal to interannual variability in density around the Canary Islands and their influence on the Atlantic meridional overturning circulation at $26^{\circ}$ N. J. Geophys. Res. Oceans, 119, 1843-1860, doi:10.1002/2013JC009416.

Dussin, R., A. Treguier, J. Molines, B. Barnier, T. Penduff, L. Brodeau, and G. Madec, 2009: Definition of the interannual experiment ORCA025-B83, 1958-2007. Laboratoire de physique des oceans (LPO) Rep. 09-02, 37 pp.

Frajka-Williams, E., W. E. Johns, C. S. Meinen, L. M. Beal, and S. A. Cunningham, 2013: Eddy impacts on the Florida Current. Geophys. Res. Lett., 40, 349-353, doi:10.1002/grl.50115.

Gill, A. E., 1982: Atmosphere-Ocean Dynamics. Academic Press, $662 \mathrm{pp}$.

Hansen, B., H. Hátún, R. Kristiansen, S. M. Olsen, and S. Osterhus, 2010: Stability and forcing of the Iceland-Faroe inflow of water, heat, and salt to the Arctic. Ocean Sci., 6, 1013-1026, doi:10.5194/os-6-1013-2010.

Heimbach, P., C. Wunsch, R. Ponte, G. Forget, C. Hill, and J. Utke, 2011: Timescales and regions of the sensitivity of Atlantic meridional volume and heat transport magnitudes: Toward observing system design. Deep-Sea Res. II, 58, 1858-1879, doi:10.1016/j.dsr2.2010.10.065.

Hewitt, H. T., D. Copsey, I. D. Culverwell, C. M. Harris, R. S. R. Hill, A. B. Keen, A. J. McLaren, and E. C. Hunke, 2011: Design and implementation of the infrastructure of HadGEM3: The next-generation Met Office climate modelling system. Geosci. Model Dev., 4, 223-253, doi:10.5194/ gmd-4-223-2011.

Hirschi, J. J.-M., and J. Marotzke, 2007: Reconstructing the meridional overturning circulation from boundary densities and the zonal wind stress. J. Phys. Oceanogr., 37, 743-763, doi:10.1175/JPO3019.1.

_ J. Baehr, J. Marotzke, J. Stark, S. A. Cunningham, and J.-O. Beismann, 2003: A monitoring design for the Atlantic meridional overturning circulation. Geophys. Res. Lett., 30, 1413, doi:10.1029/2002GL016776.

_, P. Killworth, and J. Blundell, 2007: Subannual, seasonal and interannual variability of the North Atlantic meridional overturning circulation. J. Phys. Oceanogr., 37, 1246-1265, doi:10.1175/JPO3049.1.

Houghton, J. T., Y. Ding, D. J. Griggs, M. Noguer, P. J. van der Linden, and D. Xiaosu, Eds., 2001: Climate Change 2001: The Scientific Basis. Cambridge University Press, 881 pp.

Hunke, E. C., W. H. Lipscomb, A. K. Turner, N. Jeffery, and S. Elliott, 2013: CICE: The Los Alamos Sea Ice Model documentation and software user's manual version 5.0. Los Alamos National Laboratory Rep. LA-CC-06-012, 115 pp. [Available online at http://oceans11.lanl.gov/trac/CICE/attachment/wiki/ WikiStart/cicedoc.pdf?format=raw.]

Jayne, S. R., and J. Marotzke, 2001: The dynamics of wind-induced ocean heat transport variability. Rev. Geophys., 39, 385-411, doi:10.1029/2000RG000084.

Johns, W. E., and Coauthors, 2011: Continuous, array-based estimates of Atlantic Ocean heat transport at $26.5^{\circ}$ N. J. Climate, 24, 2429-2449, doi:10.1175/2010JCLI3997.1.

Kanzow, T., and Coauthors, 2007: Flow compensation associated with the meridional overturning. Science, 317, 938-941, doi:10.1126/science.1141293. 
- and Coauthors, 2010: Seasonal variability of the Atlantic meridional overturning circulation at $26.5^{\circ} \mathrm{N}$. J. Climate, 23, 5678-5698, doi:10.1175/2010JCLI3389.1.

Large, W. G., and S. Yeager, 2009: The global climatology of an interannually varying air-sea flux data set. Climate Dyn., 33, 341-364, doi:10.1007/s00382-008-0441-3.

Latif, M., and Coauthors, 2004: Reconstructing, monitoring, and predicting decadal-scale changes in the North Atlantic thermohaline circulation with sea surface temperature. Science, 17, 1605-1614, doi:10.1175/1520-0442(2004)017<1605: RMAPMC $>2.0 . \mathrm{CO} ; 2$.

Madec, G., 2008: NEMO ocean engine. IPSL, Note du Pôle de Modélisation No. 27, 209 pp.

Marsh, R., S. A. Josey, B. A. de Cuevas, L. J. Redbourn, and G. D Quartly, 2008: Mechanisms for recent warming of the North Atlantic: Insights gained with an eddy-permitting model. J. Geophys. Res., 113, C04031, doi:10.1029/2007JC004096.

Matei, D., J. Baehr, J. H. Jungclaus, H. Haak, W. A. Mller, and J. Marotzke, 2012: Multiyear prediction of monthly mean Atlantic meridional overturning circulation at $26.5^{\circ} \mathrm{N}$. Science, 335, 76-79, doi:10.1126/science.1210299.

McCarthy, G., and Coauthors, 2012: Observed interannual variability of the Atlantic meridional overturning circulation at $26.5^{\circ} \mathrm{N}$. Geophys. Res. Lett., 39, L19609, doi:10.1029/2012GL052933.

Meinen, C. S., M. O. Baringer, and R. F. Garcia, 2010: Florida Current transport variability: An analysis of annual and longer-period signals. Deep-Sea Res. I, 57, 835-846, doi:10.1016/j.dsr.2010.04.001.

National Geophysical Data Center, 2006: ETOPO2v2 global gridded 2-minute database. [Available online at http://www. ngdc.noaa.gov/mgg/fliers/01mgg04.html.]

Ortega, P., E. Hawkins, and R. Sutton, 2011: Processes governing the predictability of the Atlantic meridional overturning circulation in a coupled GCM. Climate Dyn., 37, 1771-1782, doi:10.1007/s00382-011-1025-1.

Penduff, T., M. Juza, L. Brodeau, G. Smith, B. Barnier, J.-M. Molines, A.-M. Treguier, and G. Madec, 2010: Impact of global ocean model resolution on sea-level variability with emphasis on interannual time scales. Ocean Sci., 6, 269-284, doi:10.5194/os-6-269-2010.

Persechino, A., J. Mignot, D. Swingedouw, S. Labetoulle, and E. Guilyardi, 2013: Decadal predictability of the Atlantic meridional overturning circulation and climate in the IPSLCM5A-LR model. Climate Dyn., 40, 2359-2380, doi:10.1007/ s00382-012-1466-1.
Rayner, D., and Coauthors, 2011: Monitoring the Atlantic meridional overturning circulation. Deep-Sea Res. II, 58, 1744-1753, doi:10.1016/j.dsr2.2010.10.056

Sinha, B., A. T. Blaker, J. J.-M. Hirschi, S. Bonham, M. Brand, S. Josey, R. Smith, and J. Marotzke, 2012: Mountain ranges favour vigorous Atlantic meridional overturning. Geophys. Res. Lett., 39, L02705, doi:10.1029/2011GL050485.

Sturges, W., and B. G. Hong, 1995: Wind forcing of the Atlantic thermocline along $32^{\circ} \mathrm{N}$ at low frequencies. J. Phys. Oceanogr., 25, 1706-1715, doi:10.1175/1520-0485(1995)025<1706: WFOTAT $>2.0 . \mathrm{CO} ; 2$.

Sverdrup, H., 1947: Wind-driven currents in a baroclinic ocean; with application to the equatorial currents of the eastern Pacific. Proc. Natl. Acad. Sci. USA, 33, 318-326, doi:10.1073/ pnas.33.11.318.

Thomas, M. D., A. M. de Boer, D. P. Stevens, and H. L. Johnson, 2012: Upper ocean manifestations of a reducing meridional overturning circulation. Geophys. Res. Lett., 39, L16609, doi:10.1029/2012GL052702.

Timmermann, A., H. Goosse, G. Madec, T. Fichefet, C. Ethe, and V. Dulière, 2005: On the representation of high latitude processes in the ORCA-LIM global coupled sea ice-ocean model. Ocean Modell., 8, 175-201, doi:10.1016/j.ocemod.2003.12.009.

Trenberth, K., and J. Caron, 2001: Estimates of meridional atmosphere and ocean heat transports. J. Climate, 14, 3433-3443, doi:10.1175/1520-0442(2001)014<3433:EOMAAO >2.0.CO;2.

Valcke, S., 2006: Oasis3 user guide. PRISM Support Initiative Rep. 3, CERFACS, Toulouse, France, 64 pp.

Walters, D. N., and Coauthors, 2011: The Met Office Unified Model Global Atmosphere 3.0/3.1 and JULES Global Land 3.0/3.1 configurations. Geosci. Model Dev., 4, 919-941, doi:10.5194/gmd-4-919-2011.

Weaver, A. J., and Coauthors, 2012: Stability of the Atlantic meridional overturning circulation: A model intercomparison. Geophys. Res. Lett., 39, L20709, doi:10.1029/2012GL053763.

Wunsch, C., 2005: The total meridional heat flux and its oceanic and atmospheric partition. J. Climate, 18, 4374-4380, doi:10.1175/ JCLI3539.1.

- 2011: The decadal mean ocean circulation and Sverdrup balance. J. Mar. Res., 69, 417-434, doi:10.1357/ 002224011798765303.

- and P. Heimbach, 2009: The global zonally integrated ocean circulation, 1992-2006: Seasonal and decadal variability. J. Phys. Oceanogr., 39, 351-368, doi:10.1175/ 2008JPO4012.1. 